\section{PUERPERAL INSANITY.*}

BY ROBERT .JONES, M.D.LoND., B.S., F.R.C.S.ENG., Medical Superintendent of the London County Asylum, Claybury.

\section{INTRODUCTION.}

THE reproductive process is one of the most fundamental and imperative activities that operates in Nature. It is not limited to the reflexes involving the special instruments of reproduction, for it affects the whole organism; it depends upon vital protoplasmic bodily states, and includes most of the elementary excitations of which man is capable-the various sensations and sentiments, the pleasure of possession, admiration, self-esteem, love of approbation, reverence, exalted sympathies, and certain physiological wants ; all of them enter into this great " complex," which involves the most powerful as well as the most compound of the feelings.

This process in certain constitutions depending upon temperament, diathesis, and heredity, is apt to be disturbed which is evidence, if any were needed, that the idea of mind and body being separate and independent is radically false, and that bodily phenomena accompanying states of feeling are not factors external and negligible, foreign to psychology, and without interest to it.

When disturbance takes place during the fulfilment or after the immediate completion of this process, it converts (as Clouston states) the most joyous time of life into one of fearful anxiety, and, short of death, no event is so great a shock to all concerned, for the perfection of the providence for childhood is destroyed by disease, and the strongest affection turns to hatred and becomes a danger.

Those who have studied the reproductive life of woman admit that gestation is attended with much nervous disturbance in many, and some nervous disturbance in all ; the intimate sympathetic connection of the mammae with the gravid uterus gives rise in normal persons to various forms of neuralgia, severe headaches, dizziness, and insomnia, whereas in highly-susceptible persons these changes of disposition and character become so marked that irritability, fractiousness, and despondency may and do amount to actual insanity; and although this period of life is less liable to insanity than any other, the dynamical changes in the nervous currents are so great that insanity does actually occur about once in every 700 confinements. As against these figures, however, it may be well to quote Ripping, who, whilst acknowledging and admitting that changes in the uterus or its appendagesphysiological or pathological-may have an effect upon the mental susceptibilities of woman, denies that these are ever profound enough to become a cause of insanity.

General Statistics.

As to actual insanity during the reproductive life, and connected with it, the report of the Lunacy Commissioners (1900) shows that of all occurring insanity among women of all ages, the yearly average number of admissions for the five years 1894 to 1898 inclusive due to pregnancy, parturition, the puerperal state, and lactation bears the ratio of 7.2 in the private class, and 8.4I in the poorer classes to the total yearly average of admissions. The proportion is somewhat higher, as might be expected, among the poorer insane during the period of lactation, but that due to parturition and its attendant stage is higher among the well to do. At Claybury the statistics for 1900 correspond very closely with those of the Lunacy Commissioners' report, the number due to the causes under consideration being 7 per cent. of all occurring insanity, and ro per cent. when compared to those admitted during the child-bearing period, calculated as between 15 and 45 years. I note that Dr. Clouston ${ }^{1}$ gives the percentage of the insanities of childbed, nursing, and pregnancy as 9 per cent. of all female cases admitted under his care for nine years. Dr. Warnock in his report for the Egyptian Asylum in Cairo during the same period, gives the proportion of ro per cent. of this class to all occurring insanity among females.

* Portions of this paper formed the introduction to a discussion on Puerperal Insanity in the Section of Psychological Medicine at the Annual Meeting of the British Medical Association, held at Cheltenham, JulyAugust, rgor.
The cases out of which my numbers are taken represent about 3,500 female patients, who were received into the asylum during the past eight years. They exclude all those transferred from other asylums suffering from chronic and terminal mental conditions, although in many instances the insanity of these was due to puerperal conditions, but we ourselves have no definite record of this. Out of the 3,500 admissions, 259 cases were admitted suffering from insanity, for which reason pregnancy, confinement, the puerperal state, or lactation was assigned as a cause, a proportion of 7.4 per cent., and these are comprised as follows: 56 were from pregnancy, a proportion of 21.62 per cent., 49 of these being delivered in Claybury; 120 occurred during the puerperal period, a proportion of 46.33 per cent. ; and 83 were associated with lactation, a proportion of $\mathbf{3 2 . 4 3}$ per cent. Dr. Batty Tuke, quoting 105 cases, gives the proportion of 18.06 per cent. for the insanity of pregnancy, 47.09 for that accompanying the puerperal period, and 34.8 for that accompanying lactation. Marce, ${ }^{3}$ quoting 310 cases, gives the proportion of 8.06 per cent. for pregnancy, 58.06 for the puerperal period, and 30.3 for lactation. Dr. Clouston, quoting 141 cases, gives roughly the proportion as 5 for the puerperal period, 4 for lactation, and I for pregnancy. My statistics tend to agree much more with those of Batty Tuke, but I am unable to throw any light upon the apparent discrepancy with others. Dr. Menzies, in a very interesting and complete analysis of 140 cases published in the American Journal of Insanity for 1893, gives the percentage of 13.5 cases of puerperal insanity among those occurring in the county of Lancashire and admitted into Rainhill Asylum. In the annual report of the asylums of Iondon for 1900 there were 120 puerperal cases admitted out of a total of 2,600 female patients, a proportion of less than 5 per cent., but a large number of the total were transfers of chronic cases from other asylums owing to the recent opening of two of the new asylums of London. During the same year the births of l.ondon are given as 132,652, which gives the approximate ratio of 1 case of puerperal insanity admitted into asylums for every I, 100 births.

In Dr. Menzies's paper, dealing with Liverpool more especially, he calculates the ratio to be I for every 700 births; but Dr. Clouston gives the proportion of puerperal insanity as $I$ in every 400 confinements, and this high average clearly includes all cases, whether treated in their own homes, institutions, or special hospitals, and are probably based upon statistics of maternity hospitals, public and private practice. M. D. Macleod gives the ratio as I for every 469 , of which about one-fourth only come into asylums. Pedler, in an interesting article, ${ }^{4}$ quoting Johnston and Sinclair, gives the relation of puerperal insanity as 1 in every 528 confinements. In his paper he gives the history of 76 cases.

\section{Division of Disease.}

As to the division of insanity for these periods, the classification which is customary is (1) that which occurs during pregnancy, (2) that from the date of parturition to gix weeks after confinement, which in this paper we shall refer to technically as "puerperal" insanity, and (3) insanity occurring during lactation, and dating from six weeks after confinement. This classification must not be taken as suggesting a type of insanity, and it is more convenient than accurate.

The insanity of lactation is calculated to date six weeks after confinement, under the impression that involution of the uterus is then complete, although authorities differ upon this point, for some consider involution at this date to be only half complete, and not accomplished under three months. Moreover, the secretion of milk commences within the first few days of confinement in the majority of women, and is not infrequently accompanied with constitutional disturbance, but the exhaustion and drain due to nursing is probably not evidenced until the process has gone on for some time, and six weeks is generally agreed upon as the commencement of this period.

As to the types of insanity corresponding to these periods, my experience leads me to conclude that there is no type associated either with pregnancy or lactation, but with parturition and the period immediately succeeding it the case is different, the insanity presents such a marked delirium with wildness and delusions of a hallucinatory character, in which 
religious and erotic features become so prominent that I recognize an almost distinct nosological entity, a view I am bound to confess which is not supported by high authorities. The ratio which these three divisions bear to each other in my 259 cases is -4 of puerperal, 3 of lactation, and 2 of pregnancy. As already stated, Batty Tuke gives the relation as 2.6 puerperal, I.9 lactation, and I pregnancy ; and Clouston, as 5, 4, and I respectively; a relatively smaller number of cases occurring before delivery in the latter's experience.

It would appear in some cases that marked mental disturbance takes place during the period of gestation, not amounting to actual insanity, but culminating in acute mania during the later puerperal period; also that some mental alienation during this period may culminate in actual insanity during lactation. The relationship between the various forms of nerve-cell reduction and consequent psychic changes requires further elucidation, and may well form one of the subjects for discussion.

\section{General Characters.}

\section{I.-Primiparae-Civil State and Illegitimacy.}

Changes of so farreaching a character as gestation implies, with all the nervous excitation and psychic changes involved in the full development of the reproductive process, together with the arousal of maternal instincts for the first time, must cause many phases of mental condition, varying from vague fears and morbid dread to exalted feelings and eager expectations. The introspective life consequent upon more or less retirement during this period has many actions and reactions. In the predisposed these new relationships and changes may give rise to morbid mental action resulting in insanity, and we should expect this to be more marked among first pregnancies, more especially in the single, where the moral shock of disappointment and shame in addition to the nervous exhaustion becomes an additional strain.

Of the 56 cases of pregnancy no fewer than 14 (25 per cent. or one-fourth) were first confinements, and of these i1 (78 per cent.) occurred in single women, who were 14 in number, whilst thefifirst confinements among married women amounted to only 3 out of a total of 40, namely, less than 6 per cent., 12 per cent. were second confinements, 17 per cent. were third, 12 per cent. were fourth, 22 per cent. were fifth, and 15 per cent. were between the sixth and thirteenth.

As to illegitimacy, of the 259 cases 12 per cent. of the insanity was among single women, and of this proportion 25 per cent. were among the pregnancies, 12 per cent. among the puerperal cases, and only 3 per cent. among the lactation cases, but the proportion of single women to married in the total puerperal cases is only i4 per cent., in the lactation only 3.7,
TABLE 1.-Showing the Civil State of those Suffering from First Attacks of Insanity.

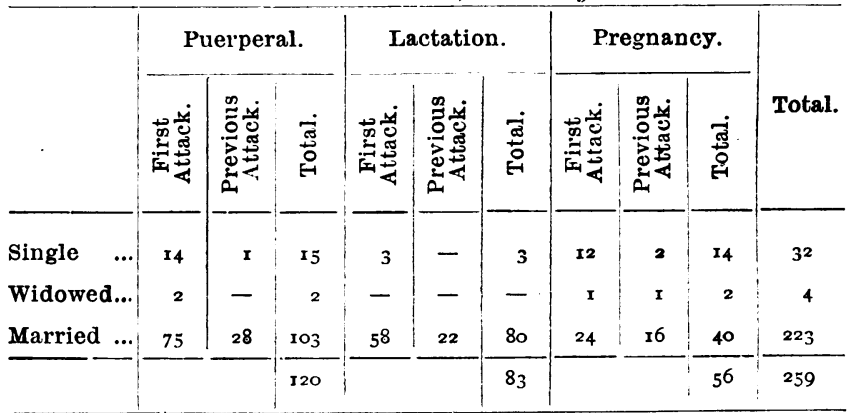

TABLE III.-Showing Civil State, Ages, and Heredity of " First" Confinements.

\begin{tabular}{l|l|l|l|c|c}
\hline \multicolumn{3}{c}{ Pregnancy. } \\
\hline
\end{tabular}

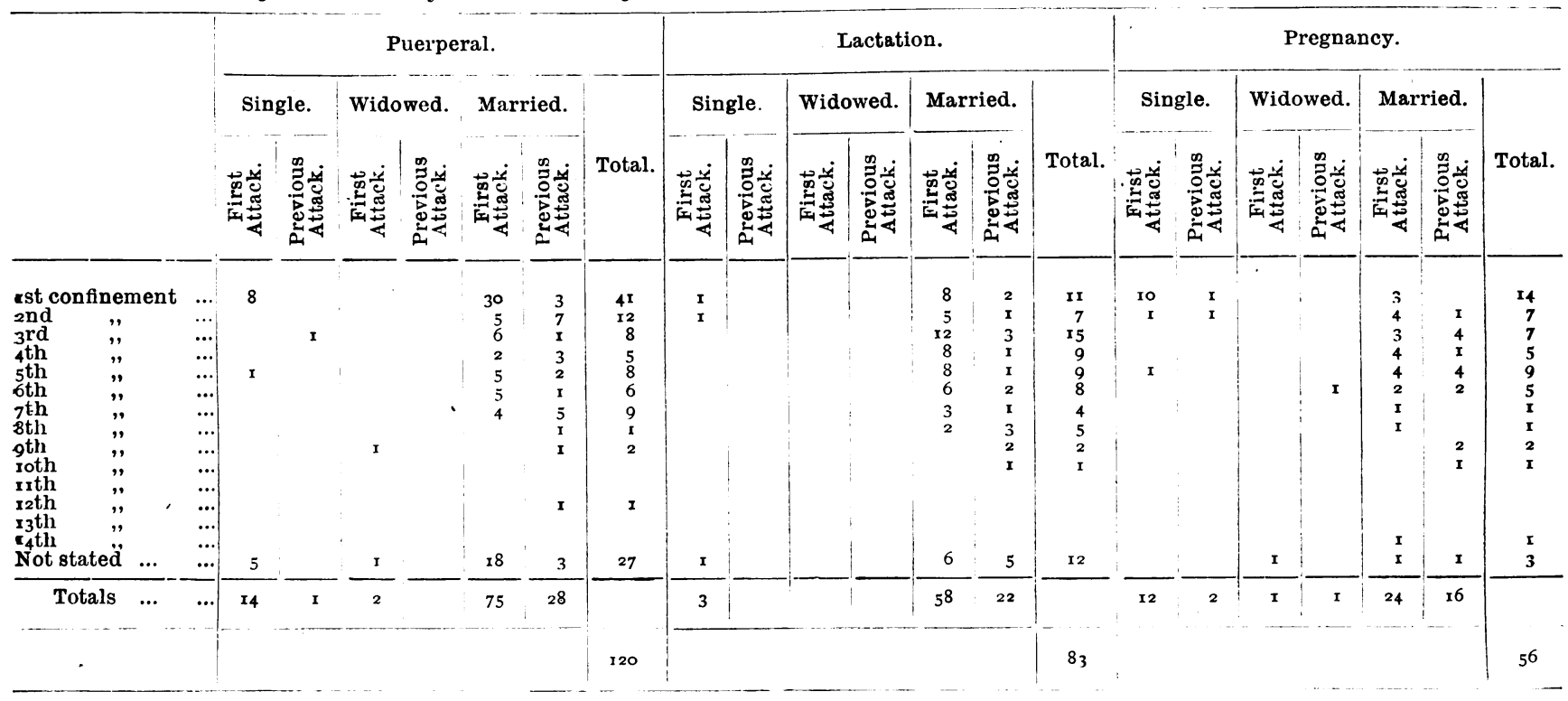


whereas, as stated in those suffering from the insanity of pregnancy, it is 32 per cent.

Dr. Clouston states that in Scotland, where illegitimacy is more common, 25 per cent. of his cases of puerperal insanity occurred among single women. Dr. Bevan Lewis, quoting 66 cases, gives a ratio of only ro per eent. among single women; and as his statistics deal with a total female insane population of 1,810 cases, among whom the proportion of single to married was I.4, the proportion of puerperal cases among those who had illegitimate offspring is exceptionally low. Dr. Menzies gives a percentage of only 7.1 of illegitimates among his 140 cases, which is lower than that among the general admission.

The incilence of illegitimacy in the general population varies greatly in different counties. In Middlesex and Essex, which are the lowest (as compared with Cumberland, 70 per $1, \infty 00$ births, and Scotland, which is probably higher still), it is 29 illegitimate births per 1,000 legitimate, a proportion of I illegitimate to every 34 legitimate.

In my cases, out of 259 insane puerperal women 32 were single, a proportion of over 8 to 1 , but the proportion of married to single in the general asylum population is 1.7 to $I$, which argues a considerably increased liability to insanity among single puerperal women, the liability being nearly four times as much.

\section{II.-Form of Insanity and Onset.}

Of the 259 cases, 60 per cent. were married women suffering from their first attack, and 25 per cent. were married women who had suffered from previous attacks. One of my patients had suffered from an attack of insanity with each of twelve children, and another with nine, each closing the scene by becoming chronic and incurable at the climacteric. As to the cases of insanity of pregnancy in single women, some of these were weak minded, with weakened emotional inhibition, unable, therefore, to restrain their passion, and thus were more readily tempted. They were of the type which is also less likely to be helped and more liable to neglect, disappointment, and shame. Taking single and married together, they suffered in about equal proportion from melancholia and mania, but the acute form of melancholia was more intense than that noticed in mania. Especially was the insanity of an unfavourable form among single women, for of the 56 cases, 4 were epileptics ( 1 single woman), 2 general paralytics, and 2 were congenital imbeciles, also single women. It has been stated that insanity was more common when the sex of the child was male. In 44 of my cases the sex of the child was ascertained, the sexes were equally divided, and $I$ am unable to bear out the truth of the above statement.

Of the puerperal cases, more suffered from mania than melancholia, and, again, more from the acute form of mania than the same of melancholia. Of the 120 cases, 1 only was epileptic.

Of the 83 lactational cases, on the other hand, a greater proportion suffered from the depressed than the exalted variety of insanity.
TABLE IV.-Showing Sex of Infant in Cases of Insanity of Pregnancy.

\begin{tabular}{l}
\hline \\
\hline
\end{tabular}

The onset of insanity in this class is either sudden or gradual.

Table VI.-Showing Onset Compared with the Form of Insanity

\begin{tabular}{|c|c|c|c|c|c|c|c|}
\hline \multirow{2}{*}{ 一 } & \multicolumn{3}{|c|}{ Puerperal. } & \multicolumn{3}{|c|}{ Lactation. } & \multirow{2}{*}{$\begin{array}{l}\text { Combined } \\
\text { Total. }\end{array}$} \\
\hline & Mania. & $\begin{array}{l}\text { Melan- } \\
\text { cholia. }\end{array}$ & Total. & Mania. & $\begin{array}{l}\text { Melan- } \\
\text { cholia. }\end{array}$ & Total. & \\
\hline Sudden ... & 35 & 10 & 45 & 7 & 2 & 9 & 54 \\
\hline Gradual ... & II & 22 & 33 & It & 26 & 37 & 70 \\
\hline Unknown.. & $\mathbf{I}$ & - & $\mathbf{I}$ & - & - & - & I \\
\hline Totals ? & 47 & $3^{2}$ & 79 & 18 & 28 & 46 & 125 \\
\hline
\end{tabular}

The onset in the puerperal cases was sudden more often than gradual, and the gradual onset characterized the advent of melancholia twice as often as mania. Clouston states that the nearer the insanity is to the confinement in point of time the more acute the symptoms, and this accords with my experience. It has been my experience, also, that when the onset is more gradual and the form is melancholia, the termination is more often in dementia. Also in the melan cholia cases there has been more tendency before admission to wander and go away from home.

Of the 259 total cases 102 had a sudden onset, of whom 68 recovered, and over 30 died or became chronic, a proportion of more than two to one; whereas of the 155 cases with a gradual

TABLE V.-Showing Form of Insanity and the Civil State.

\begin{tabular}{|c|c|c|c|c|c|c|c|c|c|c|c|c|c|}
\hline \multirow{2}{*}{ - } & \multicolumn{4}{|c|}{ Puerperal. } & \multicolumn{5}{|c|}{ Lactation. } & \multicolumn{3}{|c|}{ Pregnancy. } & \multirow{2}{*}{$\begin{array}{l}\text { Com- } \\
\text { bined } \\
\text { Tctal. }\end{array}$} \\
\hline & Single. & Widowed & M arried. & Total. & Single. & Widowed & $M$ arried. & Total. & Single. & Widowed & Married. & Total. & \\
\hline $\begin{array}{cc}\text { Mania } & \ldots \\
\text { Acute } & \ldots \\
\text { Chronic } & \ldots \\
\text { Eplileptic } & \ldots\end{array}$ & $\begin{array}{l}2 \\
5\end{array}$ & 1 & $\begin{array}{r}13 \\
42 \\
x \\
1\end{array}$ & $\begin{array}{r}15 \\
48 \\
1 \\
1\end{array}$ & I & i & $\begin{array}{r}14 \\
20 \\
3\end{array}$ & $\begin{array}{r}14 \\
21 \\
3\end{array}$ & $\begin{array}{l}I \\
3\end{array}$ & $\begin{array}{l}\text { I } \\
\text { I }\end{array}$ & $\begin{array}{r}5 \\
11 \\
2 \\
3\end{array}$ & $\begin{array}{r}7 \\
15 \\
2 \\
3\end{array}$ & $\begin{array}{r}36 \\
84 \\
6 \\
4\end{array}$ \\
\hline $\begin{array}{cc}\text { Melancholia } & . . \\
\text { Acute } & \ldots \\
\text { Chronic } & \ldots \\
\text { Epileptic } & \ldots\end{array}$ & $\begin{array}{l}3 \\
5\end{array}$ & $\mathbf{I}$ & $\begin{array}{r}17 \\
25 \\
1\end{array}$ & $\begin{array}{r}20 \\
31 \\
x\end{array}$ & 2 & & $\begin{aligned} 11 \\
29 \\
1 \\
1\end{aligned}$ & $\begin{aligned} 11 \\
31 \\
I \\
1\end{aligned}$ & $\begin{array}{l}2 \\
4 \\
x \\
x\end{array}$ & & $\begin{array}{r}5 \\
11 \\
1\end{array}$ & $\begin{array}{r}7 \\
15 \\
2 \\
1\end{array}$ & $\begin{array}{r}38 \\
77 \\
4 \\
2\end{array}$ \\
\hline \multirow[t]{3}{*}{$\begin{array}{l}\text { Delusional insanity } \quad \ldots \\
\text { General paralysis } \\
\text { Congenital imbecility... }\end{array}$} & & & 3 & 3 & & & I & I & 2 & & 2 & $\begin{array}{l}2 \\
2\end{array}$ & $\begin{array}{l}3 \\
3 \\
2 \\
\end{array}$ \\
\hline & 15 & 2 & 103 & & 3 & & 80 & & 14 & 2 & 40 & & \\
\hline & & & & 120 & & & & 83 & & & & $5^{6}$ & 259 \\
\hline
\end{tabular}


TaBLE VII.-Showing the Onset in all Cases under Treatment.

\begin{tabular}{|c|c|c|c|c|c|c|c|c|}
\hline \multirow{2}{*}{-} & \multicolumn{2}{|c|}{ Puerperal. } & \multicolumn{2}{|c|}{ Lactation. } & \multicolumn{2}{|c|}{ Pregnancy. } & \multicolumn{2}{|c|}{ Combined. } \\
\hline & $\begin{array}{l}\text { Sud- } \\
\text { den. }\end{array}$ & $\begin{array}{l}\text { Gra- } \\
\text { dual. }\end{array}$ & $\begin{array}{l}\text { Sud- } \\
\text { den. }\end{array}$ & $\begin{array}{l}\text { Gra- } \\
\text { dual. }\end{array}$ & $\begin{array}{l}\text { Sud- } \\
\text { den. }\end{array}$ & $\begin{array}{c}\text { Gra. } \\
\text { dual. }\end{array}$ & $\begin{array}{l}\text { Sud- } \\
\text { den. }\end{array}$ & $\begin{array}{l}\text { Gra- } \\
\text { dual. }\end{array}$ \\
\hline $\begin{array}{c}\text { Recover- } \\
\text { ed }\end{array}$ & 45 & 33 & 9 & 37 & 14 & II & 68 & $8 \mathrm{I}$ \\
\hline Relieved \{ & 3 & 6 & 2 & 3 & I & 2 & 6 & II \\
\hline $\left.\begin{array}{l}\text { Chronic } \\
\text { (resident) }\end{array}\right\}$ & 8 & II & 5 & $I_{3}$ & 3 & 13 & 16 & 37 \\
\hline Died \{ & 7 & 5 & 3 & II & 2 & 10 & 12 & 26 \\
\hline \multirow[t]{2}{*}{ Totals ... } & 63 & 55 & 19 & 64 & 20 & $3^{6}$ & 102 & $\mathbf{1 5 5}$ \\
\hline & \multicolumn{2}{|c|}{$\begin{array}{c}18^{*} \\
*_{2} \text { not stated, } \\
120\end{array}$} & \multicolumn{2}{|c|}{83} & \multicolumn{2}{|c|}{$5^{6}$} & \multicolumn{2}{|c|}{$\begin{array}{c}257^{*} \\
*_{2} \text { not stated, } \\
259\end{array}$} \\
\hline
\end{tabular}

onset only 81 recovered, and over 70 became chronic or died a proportion of recoveries of only about 8 to 7 . Of those resident and chronic, or died, over 50 per cent. had a gradual

TABLE VIII.-Showing Onset of Disease previous to Admission in the Puerperal and Lactation Cases, and how far Pregnant on Admission in the Pregnancy Cases. Puerperal.-Onset before admission.

\begin{tabular}{|c|c|c|c|c|c|c|c|}
\hline \multirow[b]{2}{*}{-} & \multicolumn{2}{|c|}{ Single. } & \multicolumn{2}{|c|}{ Widowed. } & \multicolumn{2}{|c|}{ Married. } & \multirow{2}{*}{ 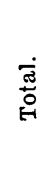 } \\
\hline & 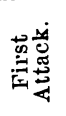 & 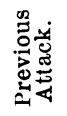 & 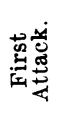 & 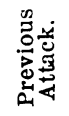 & 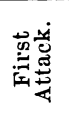 & 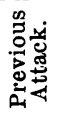 & \\
\hline 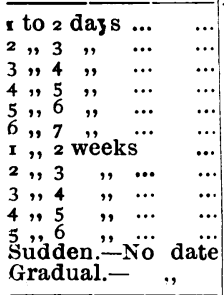 & $\begin{array}{l}3 \\
5 \\
4 \\
2\end{array}$ & I & I & & $\begin{array}{r}4 \\
5 \\
3 \\
1 \\
22 \\
11 \\
12 \\
10 \\
5 \\
2 \\
2\end{array}$ & $\begin{array}{l}\text { I } \\
\text { 2 } \\
\text { I } \\
4 \\
5 \\
5 \\
4 \\
2 \\
\text { I } \\
2\end{array}$ & $\begin{array}{r}30 \\
22 \\
17 \\
18 \\
10 \\
1 \\
4\end{array}$ \\
\hline & $r_{4}$ & I & 2 & & 75 & 28 & \\
\hline Totals & & & & & & & 120 \\
\hline
\end{tabular}

Lactation.-Onset before admission.

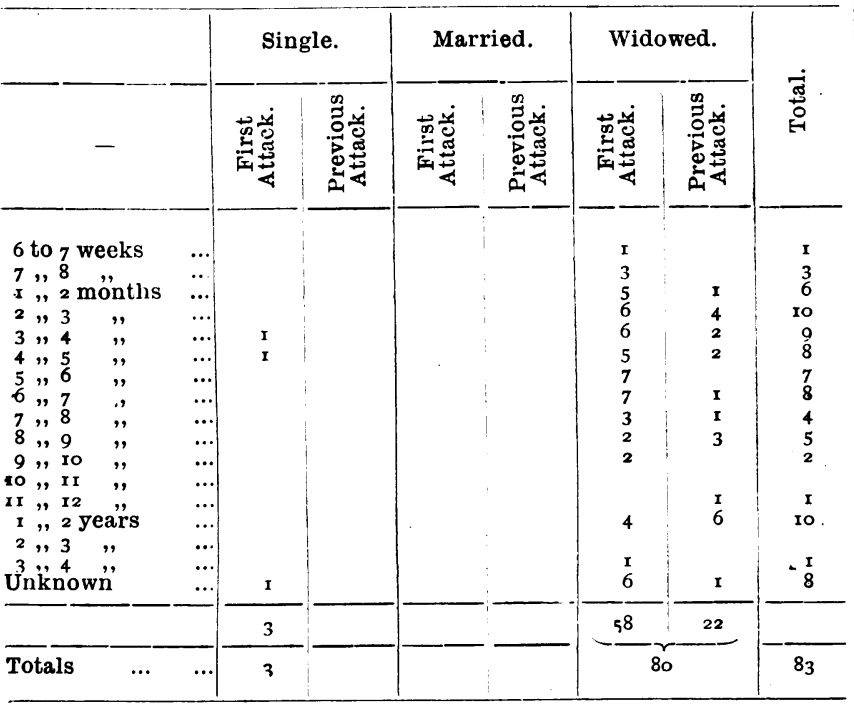

TABLE VIII.-(Continued).

Pregnancy.-Pregnant on admission.

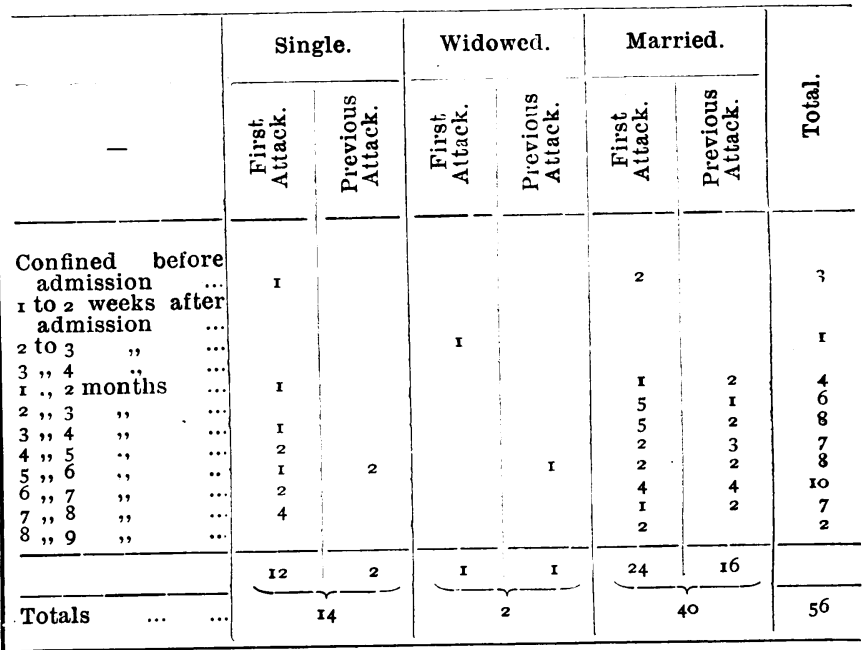

onset of insanity. In the 83 lactation cases the onset was equally frequent between the second and third month, and the first and second years, and was gradual in more than 68 per cent. The onset next most frequent was between the third and fourth month, and then between the fourth and fith and sixth and seventh month, and it was gradual much more often than sudden in these also. In the 56 pregnancy cases, 49 of whom were delivered in Claybury and 3 before admission, the onset occurred before the third month in 25 per cent., after the fifth month in 48 per cent., and aiter the sixth month in 34 per cent. In these the onset was also more often gradual, and $I$ am inclined to think that the strain during the last months of pregnancy, and immediately before parturition, is more likely to unbalance a mentally unstable woman than that attending the early changes of pregnancy, and this applies equally to the single and married.

III.-General Symptoms and Etiology.

The symptoms of puerperal mania in 40 per cent. ( 48 out of the 120 cases) occurred within the first two weeks, and of these more than a third occurred within the first week. In 58 per cent. of the 120 cases the first symptoms occurred within the first three weeks after confinement. The almost universal early symptom of insanity in puerperal cases is loss of sleep. The progress of the case is described by those who have the care of the patient as first sleeplessness, then a feverish and anxious restlessness, a busy concern about trivial details, distrust, a suspiciousness, loss of appetite, and a readiness to take offence when none was meant, an exacting irritability and ready reaction to outward stimulus, culminoting in wild delirious excitement and mania of the peculiar nating in wild delirious excitement and manseeplessness and headache, followed by an indefinable feeling of apprehensiveness, occur in puerperal women of hereditary nervous instability, any sudden unaccustomed stimulus of however slight a nature tends to and may presage a mental breakdown. Is is for this reason that early attention should be given to sleeplessness and headache. In some of the cases symptoms of unrest appeared upon the second day, and one of my patients was brought under treatment on this date suffering from the most violent delirium, with sensori-motor disturbances. In puerperal women the anxious expectancy of the latter months of pregnancy, followed by the subsequent exhaustion of parturition, causes this period to be one of unusual anxiety even in normal women. It is a period eminently impressionable, active and irritable for all the systems-the nervous, circulatory, secretory, and excretory-and it is one in which disordered conduct appears to result and be out of all proportion to the apparent stimulus. I have known pictures in the lyingin room become the basis upon which a regular system of delusions was weaved, and I have known a mother to injure her child because she herself has been crossed; and I have also 
known a woman attempt to jumpout of a window merely because she suffered from toothache. Suicidal promptings were most common in the lactation cases (47 per cent). In the insanity of pregnancy they occurred in $4 \mathrm{I}$ per cent., and in the puerperal cases in only 21 per cent. The "fear of insanity" acted as the apparent cause in one case, and the mental change against which she struggled came on quite suddenly whilst engaged in her domestic duties; in another the conversation of her nurse that babies were occasionally removed piecemeal ; and in a third the suggestion of a slight operation by her medical man was the apparent cause of a mental breakdown. Peculiar mistaken ideas about the baby are not infrequent; one imagined her baby was a skeleton, and that she was compelled to nurse it; another that her baby and the other children were horrid animals whom she had to destroy. Infanticidal promptings were also relatively more common in the lactation cases, and in married rather than single women. These were present in 14 per cent. of all cases of lactation, and in only to per cent. of puerperal cases. Several cases in each variety of insanity were, however, described as careless and neglectful, and having lost their love for their children.

TABLE IX.-Impulse to Infanticide.

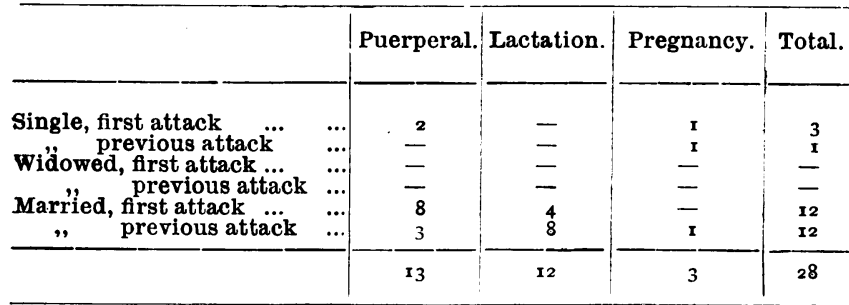

Delusions as to place and surroundings are not uncommon; women frequently imagine their children to be in bed with them, and they often wrap a portion of the clothing under the impression that it is their infant-acute hallucinatory confusional insanity. I have known religious differences well understood and tolerated between husband and wife before confinement to be the starting point of wild and terrifying religious melancholia, when the most abject fear of hell fire caused suicidal attempts.

Hearing of the accouchement of the Princess May caused one to imagine herself the identical subject of conversation. The firing at the Military Tournament, to which a visit was paid too soon after confinement, was the cause of breakdown in one case, and bad news has frequently been assigned as the cause. Is this due to septicism or some other form of toxaemia? Is it a bodily exhaustion, or is it partly mental also?

Most of the patients admitted had undergone the most severe bodily strain, for, in addition to the puerperium, they also had the care, responsibility, and management of a home under peculiar difficulties.

There is in all cases of insanity a breaking strain beyond which the crisis occurs. What this may be we have referred to under the remarks on its pathology, but such is the tendency with some authorities to look upon mental disease as essentially bodily that a mere reference to mental strain may not be out of place. We know that in ordinary life the perusal of a letter or the sudden communication of bad news may strike the stoutest to the ground; indeed, the physical accompaniments of fear are too well known to require detailing. Fear can paralyse and hope can instantaneously give soundness and vigour to the frame, as much as despair can effect the reverse. It is during the early puerperal period that care should be rigialy exercised to avoid sudden excitement, to procure sleep, and to sustain the organs in a healthy nutritive state during the process of restoration. Once atnormal conditions are started, loss of sleep occurs, hallucinations of the senses arise, and I have noticed in several instances that of the sense of smell, with suspicions of poisoning and refusal of food.

As to hallucinations of the senses; those of hearing were six times as common as any other.

Few had hallucinations of smell, touch, or taste. I have known a case where the too free administration of alcohol gave rise to the most painful hallucinations of sight; the patient imagined she saw the devil, and attempted to murder another under the impression she was killing the devil. With confusion of ideas, the patient has delusions of personal identity; she mistakes those about her for others she has seen and known, and fails to recognize her own identity or that of her baby. She develops marked antagonism to her husband; erotic delusions appear, with immodest behaviour and improper language, generall $y$ with rapid and inconsequent chatter and indecent suggestions. Marked sexual excitement, with faulty habits mingled with religious exaltation, are more often met with in this form of insanity than in any other. They appear in a person previously of pure and unblemished character, and this condition shocks and alarms everybody about her. As to the association of prurient language with sexual disturbances and religious exaltation, it must be remembered that love and religion are the two most volcanic emotions to which the human organism is liable, and when the one is disturbed, as so extensively occurs in pregnancy and parturition, the vibration naturally and readily extends to the other. Religious and sexual manifestations associated together are well known among certain classes of the insane, such as the epileptics, and they are not unknown among the sane in the lives of some religious devotees and ecstatics. As Havelock Ellis states, religion like modesty consists in the repression of natural impulses. and a certain reticence and restraint are characteristic of what is best in religion, art, and life. When the proper balance between certain definite restraint and impulse is disturbed, as occurs particularly in this form of insanity, the symptoms we have referred to as characteristic of the disease appear with painful prominence. This confusional condition passes into an absolutely uncontrollable and restless violence, accompanied with profound physical exhaustion, in which the patient presents a peculiarly glaring, wild look, with a markedly anaemic and general sallow hue. The bodily exhaustion is probably the cause of an overpowering tendency to yawning which I have frequently noticed in these cases. The gibberish nonsense, erotic, immodest conduct and bad language, the evolutions of shameless indecency, accompanied with noisy delirium and marked religious exaltation, with purposeless restlessness, characterize-sum up, if I may say so-the insanity of the puerperal period, and in this $I$ am disposed to lecognize, as already stated, a distinct type of nosological entity. In the insanity of pregnancy and lactation, my experience leads me to conclude that there are no general symptoms characteristic of these periods, and in the pregnancy cases no unanimity of opinion other than that the third stage of labour in the insane is perhaps generally precipitate can be obtained. In some there was slowness on the part of the uterus to contract after the birth of the child, and free haemorrhage occurred. The patients were described in some cases as stubborn and resistive. One case was a placenta praevia, in two cases labour came on quite suddenly. Many of the infants failed to survive their births for long, and I consider that insanity is very unfavourable to the life of the offspring, which after all may be a kindly Providence.

Insanity has been stated to occur during conception, but I have never met with such a case. Dr. Savage has divided this form into that of early and late pregnancy, but my experience is that it mainly occurs towards the end of gestation. Over 33 per cent. of this form were over six months pregnant upon admission. A transient insanity during delivery has not come under my notice. Such cases would naturally only come under the notice of the obstetrician, but they are of great medico-legal interest in view of unexpected and occasional tragic occurrences.

\section{IV.-ATracks.}

Of the r 20 puerperal cases 88 (namely, 73 per cent.), were first attacks, and of these 13 out of 15 cases were single women (namely, 86 per cent.); 19 (namely, 16 per cent.), had one previous attack ; 9 (namely, 8 per cent.), had two attacks; 9 were third attacks; 3 (nomely, 2.5 per cent.), had had four attacks, and $\mathrm{I}$, had eleven previous attacks, each at a puerperal period.

Of those cases who had first attacks mental changes had occurred in some previous confinement, but not sufficiently marked to be in an asylum. Of the lactation cases, 83 in 
number, $5^{8}$ (69 per cent.), were first attacks, and of the other 25, I3 (namely, I 5 per cent.). had one previous attack, 7 (8 per cent.), had two previous attacks; 2 ( 2 per cent.) had three previous attacks, and were suffering from the fourth; 2 were suffering from the fifth, and I from the sixth.

Of patients at Claybury, but not coming under the purview of this paper, one female was at another asylum for an attack of puerperal insanity, but she afterwards bore seven other children without an attack of insanity, and it may be worth recording that five of these children became insane.

It is interesting to notice in many of these the previous record of hysteria, although the percentage of such cases is not common. The question may be asked whether hysteria in early life increases the possibility of a mental breakdown

TaBLE X.-Showing the Number of Attacks of Insanity in the Puerperal, Lactation, and Pregnancy Cases together with Ages and Heredity of the "First" Attacks. Puerperal.

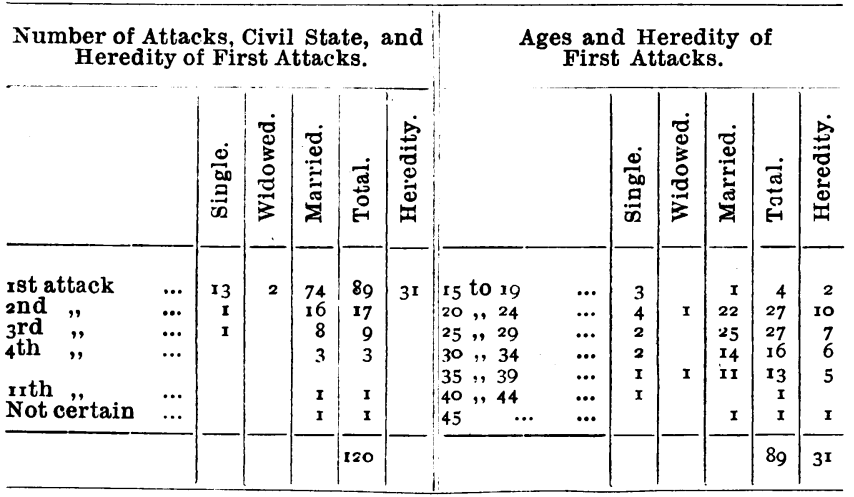

\begin{tabular}{|c|c|c|c|}
\hline : & $\begin{array}{l}\text { Analysis of Heredity in above } \\
\text { 3r Cases. }\end{array}$ & 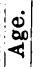 & $\begin{array}{l}\text { Analysis of Heredity in above } \\
\text { 3x Cases. }\end{array}$ \\
\hline $\begin{array}{l}19 \\
20 \\
21 \\
21 \\
21 \\
21 \\
21 \\
22 \\
22 \\
23 \\
24 \\
25 \\
25 \\
25\end{array}$ & $\begin{array}{l}\text { Mother (when pregnant) fits; four } \\
\text { brothers and sisters died fits; } \\
\text { grandfather and grandmother } \\
\text { died asthma } \\
\text { Mother Colney Hatch four times } \\
\text { Father died consumption } \\
\text { Mother suicide; aunt insane } \\
\text { Father eccentric } \\
\text { Maternal aunt insane } \\
\text { Maternal aunt insane } \\
\text { Mother insane; phthisis } \\
\text { Father intemperate } \\
\text { Brother insane: father phthisis } \\
\text { Phthisis in family } \\
\text { Parents intemperate } \\
\text { Father insane } \\
\text { Mother phthisis } \\
\text { Father insane (after patient's ad- } \\
\text { mission) } \\
\text { Father epileptic fits } \\
\text { Brother insane }\end{array}$ & $\begin{array}{l}28 \\
28 \\
30 \\
30 \\
31 \\
32 \\
32 \\
34 \\
35 \\
35 \\
37 \\
37 \\
39 \\
45 \\
3 \\
3 \\
3\end{array}$ & $\begin{array}{l}\text { Phthisis and drink } \\
\text { Parents phthisical } \\
\text { Paternal grandfather and ma- } \\
\text { ternal uncle insane; mother } \\
\text { died paralysis } \\
\text { Maternal grandfather insane } \\
\text { Father and others insane } \\
\text { Mother insane } \\
\text { Uncle and cousin insane } \\
\text { Eccentric relatives } \\
\text { Brother insane, another epi- } \\
\text { leptic and two sisters insane } \\
\text { Mother and twe } \\
\text { Maternal grandfather and uncle } \\
\text { insane } \\
\text { Paternal aunt insane; phthisis } \\
\text { in family } \\
\text { Mother and sisters insane } \\
\text { Paternal aunt insane; phthisis } \\
\text { on mother's side. }\end{array}$ \\
\hline
\end{tabular}

Lactation.

\begin{tabular}{|c|c|c|c|c|c|c|c|c|c|c|c|c|c|}
\hline \multicolumn{7}{|c|}{$\begin{array}{c}\text { Number of Attacks, Civil State, and } \\
\text { Heredity of First Attacks. }\end{array}$} & \multicolumn{7}{|c|}{$\begin{array}{l}\text { Ages and Heredity of } \\
\text { First Attacks. }\end{array}$} \\
\hline & & 离 & 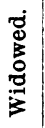 & 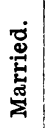 & 密 & 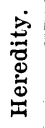 & & & 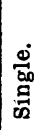 & $\begin{array}{l}0 \\
0 \\
0 \\
0 \\
0 \\
0\end{array}$ & 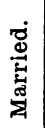 & 突 & 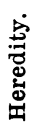 \\
\hline $\begin{array}{l}\text { ist attack } \\
\text { 2nd ", } \\
\text { 3rd ", } \\
\text { 4th ", } \\
\text { 5th ", } \\
\text { 6th ", }\end{array}$ & $\begin{array}{l}\ldots . \\
\ldots \\
\cdots \\
\cdots \\
\cdots\end{array}$ & 3 & & $\begin{array}{r}55 \\
13 \\
7 \\
2 \\
2 \\
1 \\
1\end{array}$ & $\begin{array}{r}58 \\
13 \\
7 \\
2 \\
2 \\
1\end{array}$ & 28 & $\begin{array}{rrr}20 & \text { to } & 24 \\
25 & , 2 & 29 \\
30 & \prime \prime & 34 \\
35 & \prime & 39 \\
40 & \prime & 44 \\
45 & & \end{array}$ & $\begin{array}{l}\ldots . \\
\ldots . \\
\cdots \\
\cdots\end{array}$ & $\begin{array}{l}\mathbf{I} \\
\mathbf{2}\end{array}$ & & $\begin{array}{r}9 \\
12 \\
21 \\
11 \\
I \\
I\end{array}$ & $\begin{array}{r}10 \\
14 \\
21 \\
11 \\
1 \\
1\end{array}$ & $\begin{array}{l}8 \\
6 \\
8 \\
5 \\
x\end{array}$ \\
\hline & & & & & 83 & & & & & & & $5^{8}$ & 28 \\
\hline
\end{tabular}

TABLE X.-(Continued).

Lactation (Continued).

\begin{tabular}{|c|c|c|c|}
\hline & $\begin{array}{l}\text { Analysis of Heredity in above } \\
28 \text { Cases. }\end{array}$ & 品 & $\begin{array}{l}\text { Analysis of Heredity in above } \\
28 \text { Cases. }\end{array}$ \\
\hline \begin{tabular}{l|l}
21 & 21 \\
22 & \\
22 & \\
23 & \\
24 & \\
24 & \\
24 & 26 \\
26 & 26 \\
26 & 28 \\
28 & \\
30 &
\end{tabular} & $\begin{array}{l}\text { Cardiac disease in family } \\
\text { Phthisis on father's side } \\
\text { Mother eccentric ; father drink } \\
\text { Mother and maternal aunt insane } \\
\text { Mother insane } \\
\text { Brother insane } \\
\text { Mother insane (at birth of patient) } \\
\text { Father suicide } \\
\text { Mother died of paralysis } \\
\text { Mother intemperate } \\
\text { Cousin insane } \\
\text { Paternal grandfather insane } \\
\text { Mother died in a fit } \\
\text { Brother insane } \\
\text { Mother insane ; sister insane after } \\
\text { childbirth }\end{array}$ & $\mid \begin{array}{l}30 \\
30 \\
32 \\
32 \\
33 \\
33 \\
34 \\
35 \\
35 \\
35 \\
37 \\
38 \\
38 \\
41\end{array}$ & $\begin{array}{l}\text { Maternal aunt insane } \\
\text { Parents intemperate } \\
\text { Mother insane (epileptic); aunt } \\
\text { insane } \\
\text { Father insane } \\
\text { Mother died of phthisis } \\
\text { Mother epileptic; aunt insane } \\
\text { Mother and aunt insane } \\
\text { Paternal side insane } \\
\text { Mother in asylum } \\
\text { Paralysis father's side; all } \\
\text { brothers and sisters } \\
\text { Phthisis in family } \\
\text { Mother hysterical } \\
\text { Sisters insane }\end{array}$ \\
\hline
\end{tabular}

Pregnancy.

Number of Attacks, Civil State, and
Heredity of First Attacks. $\quad \begin{gathered}\text { Ages and Heredity of } \\ \text { First Attacks. }\end{gathered}$

\begin{tabular}{|c|c|c|c|c|c|c|c|c|c|c|c|c|c|}
\hline & & 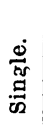 & 芯 & 莺 & 苛 & 总 & $\cdot$ & & $\frac{0}{00}$ & 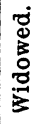 & 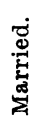 & 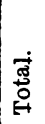 & 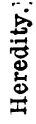 \\
\hline $\begin{array}{l}\text { ist attack } \\
\text { 2nd ", } \\
\text { 3rd " } \\
\text { 4th ", }\end{array}$ & $\begin{array}{l}\cdots \\
\cdots \\
\cdots\end{array}$ & $\begin{array}{r}12 \\
\mathbf{I} \\
\mathbf{I}\end{array}$ & I & $\begin{array}{r}24 \\
\text { II } \\
4 \\
1\end{array}$ & $\begin{array}{r}37 \\
12 \\
6 \\
1\end{array}$ & 25 & 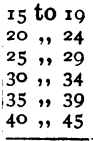 & $\begin{array}{l}\ldots . \\
\ldots \\
\ldots \\
\cdots \\
\cdots\end{array}$ & $\begin{array}{l}2 \\
6 \\
2 \\
\mathbf{1} \\
\mathbf{1}\end{array}$ & $\mathbf{I}$ & $\begin{array}{l}6 \\
7 \\
7 \\
4\end{array}$ & $\begin{array}{r}2 \\
12 \\
9 \\
8 \\
5 \\
1\end{array}$ & $\begin{array}{l}8 \\
7 \\
7 \\
3\end{array}$ \\
\hline & & & & & 56 & & & & & & & 37 & 25 \\
\hline
\end{tabular}

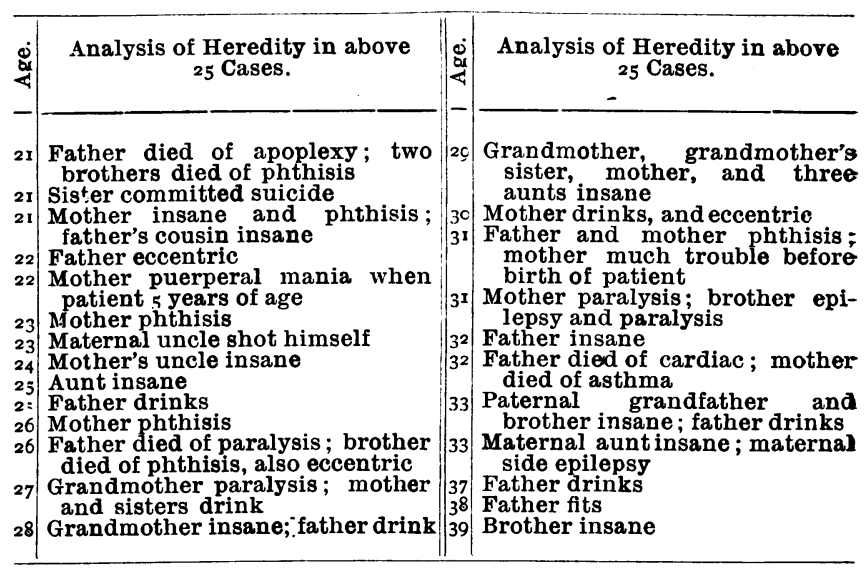

in the puerperium, and if so their marriages should be discouraged; but it must be remembered that to many girls marriage fulfils a natural expectation, and may lessen the possibility of a breakdown at the climacteric, and therefore to condemn such cases to singleness may be adding to the increase of insanity.

As to the number of the confinement after which insanity occurred, 4 I (including 8 of the 15 single women) followed the first pregnancy, or 33 per cent.

$$
\begin{aligned}
& 12 \text { followed the second confinement, equal to ro per cent. }
\end{aligned}
$$

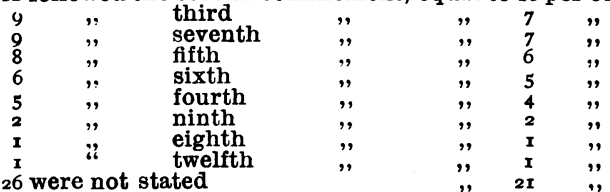

Of the lactation cases, on the other hand, the strain of 
frequent pregnancies, and the drain of prolonged suckling (in some amounting to over two years), appears to have been the cause of insanity rather than a first attack :

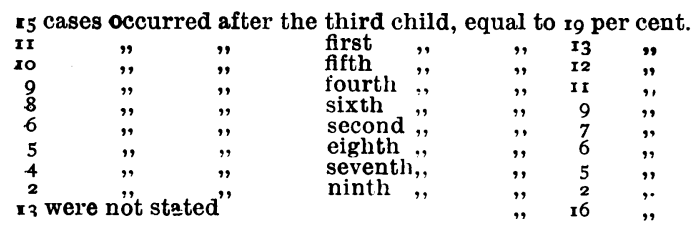

Of the pregnancy cases, ig (including 13 single women out of 15 ) out of a total of 56 cases, or 34 per cent., became insane at or during the first pregnancy, and an equal number of married women at the second and fourth. These statistics prove beyond a doubt the great moral shock of a first pregnancy especially in women with illegitimate offspring.

\section{VI.-HERedity}

Of the 259 cases 129-nearly 50 per cent.- had some hereditary predisposition either physically or mentally, and this includes both direct and collateral insanity, epilepsy, suicide, intemperance, phthisis, etc., as shown in the accompanying tables, a higher proportion than is generally ascertained. Of these 129 cases, nearly 53 per cent. had a direct hereditary history, in per cent. had a collateral, and 21 per cent. had both a collateral and a direct.

Of the total 120 puerperal cases, whether first attack or not, 5I (50 per cent.) had a faulty heredity, and this was direct maternal oftener than it was paternal. In the 89 first attacks among the puerperal cases 34 per cent. suffered from a hereditary taint, and in these maternal heredity was twice as frequent as paternal. In some of the chronic cases who did not recover, and who are still in the asylum, although no hereditary history was obtainable upon admission, one or other parent subsequently became an insane inmate of an asylum, showing that, although not apparent, the faulty strain nevertheless existed.

Of the 83 lactation cases, 58 were first attacks, 23 of these had a hereditary history, direct maternal heredity being twice as common as paternal.

In the 56 pregnancy insanities there was heredity in 82 per cent., but there was no marked difference in the maternal and paternal heredity. Of the 56 cases 14 were first attacks with a percentage heredity of 57 . It is upon the baneful influence of an evil heredity that attention should be concentrated, for it is impossible to qualify that great biological law according to which all beings endowed with life tend to repeat the elements and functions of their organism in their descendants-a law which governs the subordinate no less than the dominant characteristics, and which involves internal and external structures with their physiological and psychological consequences.

\section{V.-AGES.}

That of greatest incidence was between the ages of 25 and 29 years, both for the insanity of pregnancy and that of the puerperal period, whereas the greatest incidence in lactation cases was between 30 and 34 years, a fact which supports the view that this latter form is closely related to exhaustion, and occurs most commonly immediately after the best period of life-namely, that under 30 years.

The next period of greatest incidence in the two first classes was between 20 and 24 vears.

Of insanity among pregnant women, a high proportion26 per cent.-occurred in unmarried women, and of these 20 per cent. were under 20 years of age, the same proportion was over 30 years of age, one (a widow, illegitimate) being over 40 years. Only 3 single women out of 83 cases suffered from the insanity of lactation, which is probably due to the fact that few illegitimate infants are allowed to be nursed by their mothers. Of the first pregnancies and first attacks of insanity, 75 per cent. occurred in single women, whereas only 21 per cent. occurred in married women. Most first attacks, both in married and in single women, occurred between the ages of 20 and 24 years; but 43 per cent. of married women were over 30 years of age when suffering from the insanity of pregnancy, 50 per cent. of these being first attacks. Of the insanity during lactation and the strictly puerperal period, 4 per cent. and 12 per cent. respectively occurred in single women, i4 per cent. and 12 per cent. respectively occurred with the first child, and between the ages of 35 and 45 years, a fact which agrees with general experience and expectation that when pregnancy and parturition occur beyond the age at which restoration and recuperation naturally and readily occur, the great outlay and exhaustion consequent thereon are more likely to act as the breaking strain. The shame and worry of an illegitimate pregnancy must exercise a considerable influence as a moral factor in the production of insanity, but it is difficult to state upon which age-extreme of the reproductive life this is greater, and this is open to further inquiry.

\section{VII.-TEMPERAMENT}

Of the i2o puerperal cases 48 per cent. were described as cheerful, 15 per cent. as reserved, 7.5 per cent. as unstable, and 8 per cent. as excitable.

Of the lactation cases 42 per cent. were described as cheerful and 18 per cent. as reserved. Of the pregnancy cases $4 I$ per cent. were cheerful, 23 per cent. reserved, and 9 per cent. excitable.

TABLE XI.-Showing Appro.imate Ages.

\begin{tabular}{|c|c|c|c|c|c|c|c|c|c|c|c|c|c|c|c|c|c|c|c|c|c|c|c|}
\hline \multirow{3}{*}{\multicolumn{2}{|c|}{ Ages. }} & \multicolumn{7}{|c|}{ Puerperal. } & \multicolumn{7}{|c|}{ Lactation. } & \multicolumn{6}{|c|}{ Preguancy. } & \multirow{3}{*}{ · } & \multirow{3}{*}{$\begin{array}{c}\text { Com- } \\
\text { bined } \\
\text { Total. }\end{array}$} \\
\hline & & \multicolumn{2}{|c|}{ Single. } & \multicolumn{2}{|c|}{ Widowed. } & \multicolumn{2}{|c|}{ Married. } & \multirow{2}{*}{ 홍 } & \multicolumn{2}{|c|}{ Single. } & \multicolumn{2}{|c|}{ Widowed. } & \multicolumn{2}{|c|}{ Married. } & \multirow[b]{2}{*}{$\underset{\tilde{\sigma}}{\stackrel{\Xi}{0}}$} & \multicolumn{2}{|c|}{ Single. } & \multicolumn{2}{|c|}{ Widowed. } & \multicolumn{2}{|c|}{ Married. } & & \\
\hline & & 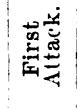 & 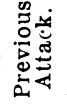 & 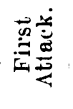 & 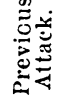 & 至泀 & 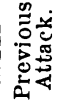 & & 易 & 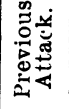 & 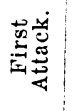 & 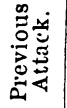 & 产 & 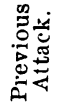 & & 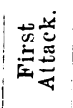 & نَّ & 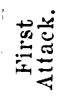 & 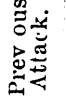 & 茪 & 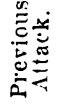 & & \\
\hline 15 & to 19 & 3 & & & & $\mathbf{I}$ & & 4 & & & 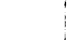 & & & & & 2 & & & & & & 2 & 6 \\
\hline 20 & , 24 & 4 & & $\mathbf{r}$ & & 22 & 2 & 29 & $\mathbf{r}$ & & & & 9 & $\mathbf{I}$ & I I & 7 & & & & 6 & $\mathbf{I}$ & 14 & 54 \\
\hline 25 & $" 29$ & 3 & $\mathbf{r}$ & & & 25 & $\mathbf{I I}$ & 40 & 2 & & & & 14 & 2 & 18 & 1 & 2 & & & 6 & 7 & 16 & 74 \\
\hline 30 & ", 34 & 2 & 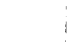 & & & 14 & 10 & 26 & & & & & 21 & 8 & 29 & $\mathbf{r}$ & & & & 7 & 5 & 13 & 68 \\
\hline 35 & , 39 & $\mathbf{I}$ & & I & & 12 & 4 & 18 & & & & & 12 & 4 & 16 & $\mathbf{I}$ & & & $\mathbf{r}$ & 4 & 2 & 8 & 42 \\
\hline 40 & $", 4$ & $\mathbf{I}$ & & & & & I & 2 & & & & & $\mathbf{I}$ & 7 & 8 & & & $1 *$ & & $\mathbf{r}$ & $\mathbf{I}$ & 3 & 13 \\
\hline 45 & $\cdot-$ & & & & & I & & $\mathbf{I}$ & & & & & I & & $\mathbf{I}$ & & & & & & & & 2 \\
\hline & & & & 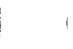 & & & & 120 & & & & & & & 83 & & & & & & & 50 & 259 \\
\hline
\end{tabular}


As to the colouring, most had brown hair and brown or grey eyes. Very few had dark hair, only two had red hair Several were described as having fair hair, but brown and dark brown greatly predominated. The colour of the eyes was noted as either dark, brown, hazel, grey, and blue. Brown hair with hazel or grey eyes greatly predominated, so also does this type normally in the London area; the dark Iberian-Mediterranean type being comparatively infrequent outside Cornwall.

1 Mental Diseases, 1883. ${ }^{2}$ Edinburgh Medical Journal, vol. x. ${ }^{3}$ Traite de a Folie des Femmes Enceintes. \& West Riding Asylum Reports, 1872 (To be continued.)

\section{A CASE OF TUMOUR OF THE CEREBRAL} CORTEX.

BY H. CECIL BARLOW, M.B.LOND., L.R.C.P., M.R.C.S., Farnborough.

THE following is a somewhat incomplete account of a case of tumour of the cerebral cortex, which is interesting in that several of the symptoms and physical signs which are diagnostic of that condition were absent.

History. - W. R, aged 57, an armourer sergeant, apparently in good health, was suddenly seized with convulsong and, rgor, which were confned to the left side of the body, beginning in and mainly affecting the face, but also the arm. During the attack $h$ as perfectiy conscious, but bat tween May ance.

Unfortunately I have been unable to obtain any account of his condition while there, but I have learned from his friends that he had one attack of convulsions.

State on Examination. - On the night of May 3 st I saw him for the first time. He was standing with head and shoulders bent forward-perfectly conscious, and appearing to understand all that was said to him, but he was vnable to articulate distinctly. There was frequent and marked spasm of the left facial muscles, and of the left arm, and to a less extent of the left leg. The mouth was open - tongue protruded, and saliva flowing from the mouth. The grasp of the left hand was decidedly weaker than that of the right. The deep reflexes were very brisk on the affected side. while sensation was markedly dulled and delayed to pain and touch on that side. The pulse-rate was 78 . He appeared free from pain The attack came on while in bed, and the twitching began in the face. He was put to bed. and a mixture of chloral and ammonium bromide adminis-
tered. There was no obtainable history of alcoholism, epilepsy, or specific disease.

Progress. - Next morning, June rst he appeared fairly comfortable having slept during the night, there was still marked twitching of the muscles of the left side of the face occurring every three or four minutes and very slight occasional spasm of the muscles of left arm. In the intervals between the spasms left facial palsy was obvious, and the left arm was decidedly weaker than the right. Temperature was normal, pulse 68, regular, good volume, moderate tension. There was no abnormal rigidity of the arterial walls. Sensation on the left side was dulled and delayed to touch and pain. An examination of the urine revealed nothing abnormal. Taste and smell were normal. Sight was good and the optic discs were normal. There was no discharge from the ears and no pain or tenderness of the head. The chest was emphysematous-the only abnormality discovered was a systolic bruit loudest at the aortic cartilage. He was ordered a liberal diet and given a mixture of bromide and potassium iodide (ten grains) three times a day. For the next four days, June 2nd, $3^{\text {rd, }}$, th and 5 th, the patient's general condition appeared to improve. The twitching gradually subsided, leaving marked facial palsy and paresis of the left arm and hand. The temperature was normal each day, and the pulse ranged between 68 and 76 . He slept comfortably at night. He complained of no pain, he was able to read his paper and converse with those about him. On June $3^{\text {rd }}$ there was a very decided increase of power in the left arm and hand, but no improvement in the face. He took his food well. On June 6th he began to be drowsy-the oromide was discontinued, but the iodide was still given-he complained of slight pain in the right parietal region. On June 7 th, 8th, gth, soth and the pain in the head passed off 0 on June 6 th, with the exception that the pain in the head passed off. On June 12 th he was more drowsy but he had no pain. The optic discs were examined and found normal. His pulse was pain, The optic discs were examined and found normal. His pulse was regular of good volume and tension, rate 68. Temperature without any preliminary coma, apparently from heart failure.

Necropsy. - I obtained leave to examine the brain. On removing the skull cap there was no abnormal appearance of the dura mater and no marked increase of tension. On exposing the brain marked injection of the vessels of the pia arachnoid over the right Rolandic area was evident. Just below the surface of the cortex, which was considerably softened for tumour the size and shape of a walnut. The main bulk of the tumour was situated in the lower portion of the ascending frontal lobe. Mr friend. Dr. Bertram Abrahams, has examined the tumour, and reports that it ir. Bertram Abrahams,

A consideration of the facts of the case would naturally lead to a diagnosis of a lesion in the right Rolandic area, but as to the nature of that lesion the data obtained did not give any very clear indication. The absence of optic neuritis, vomiting, and the very slight pain in the head all seemed to negative cerebral tumour. The short duration of the illness (thirty-three days) and the sudden termination without any preliminary stage of coma are points which are deserving of notice.

\section{MEMORANDA: \\ MEDICAL, SURGICAL, OBSTETRICAL, THERA- PEUTICAL, PATHOLOGICAL, ETc.}

THE TREATMENT OF INFLUENZA. IN the short paper in the BrITISH MEdical Journal of February 15 th I related a case of diabetes cured in a few weeks by measures exactly the opposite of those followed by the profession. 'This disease is a comparatively rare one. I now wish to speak of one of the most common and most fatal diseases of the period which may also be treated with success by methods the opposite of what are now ordinarily employed.

I allude to influenza. My first experience of influenza was in Aberdeen, when beginning my medical studies in the winter of 1836-7. The epidemic was almost universal, affecting more of the community than any I have met with since. Whole families were laid down and were absolutely helpless, and sometimes were discovered in this condition by their neighbours.

The last thing that was thought of in those days was to feed the sick, who wished for nothing, or to give them any stimulant whatever. They were absolutely left to Nature and I do not remember hearing of $a$ death during the whole epidemic ; it is quite possible that such may have occurred in old and feeble individuals, but I have no recollection of it; nor do I remember any epidemic occurring since with anything like the same severity or numbers. Common colds, which occur also in epidemics as being of a most infectious nature, got to be spoken of as influenza, but I am not aware of cases like those in Aberdeen occurring till the appearance of the severe form of the disease which originated in Russia and spread thence to this and other countries. The general method of treating disease had now completely altered, and with it the treatment of influenza. The toxic element, whatever it is, led as formerly to intense depression, but, instead of being left to Nature to be got rid of in its own way, was opposed by giving food and stimulants, both of which, especially the stimulants, stopped the natural actions of the system in expelling the poison, and in many cases led at once to a fatal result. The after-effects are too well known to need mention, and the deaths from them have been much more frequent after a more or less prolonged period than were those from the original attack. For myself I have all along treated cases of influenza on the old method of leaving them absolutely to Nature, and, so far as my memory goes, I do not remember the loss of a single case. Certainly for twenty-five years after my late colleague and successor joined me we did not lose a single case.

In Plea for a Simpler Life, and also in the preface to the conjoint volumes of Plea and Fads, I give numerous cases of patients who were cured when left to Nature, and of others which went wrong on the usual treatment of the day. Perhaps the most remarkable of the recoveries was that of an old lady of 87 , given fully at p. 87 of Plea. She has enjoyed the best of health ever since, and at the age of 94 she gives every promise of living her hundred years at least. On the other hand several cases which were treated wrongly from the beginning or were interfered with when making good progress to recovery are instances of the sad results daily occurring from what has come to be regarded by the profession as the proper method of treating the disease.

Diabetes and influenza are typical diseases which differ the one from the other as to their cause and treatment. Diabetes is the result of bad feeding and its cure is effected by a return to a more rational dietary.

In influenza an active poison has got into the system causing intense temporary depression which Nature if left free to 